\title{
Achievements and needs for the climate change scenario framework
}

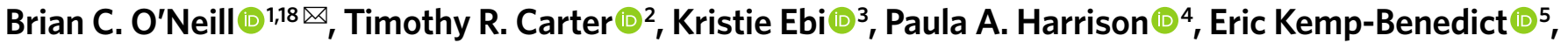 \\ Kasper Kok ${ }^{6}$, Elmar Kriegler ${ }^{7}{ }^{7}$, Benjamin L. Preston ${ }^{8}$, Keywan Riahi', Jana Sillmann ${ }^{10}{ }^{10}$, \\ Bas J. van Ruijven $\oplus^{9}$, Detlef van Vuuren ${ }^{111,2}$, David Carlisle', Cecilia Conde ${ }^{13}$, Jan Fuglestvedt $\left(\mathbb{1}^{10}\right.$, \\ Carole Green ${ }^{1}$, Tomoko Hasegawa ${ }^{14}{ }^{14}$, Julia Leininger ${ }^{15}$, Seth Monteith ${ }^{16}$ and Ramon Pichs-Madruga ${ }^{17}$
}

Long-term global scenarios have underpinned research and assessment of global environmental change for four decades. Over the past ten years, the climate change research community has developed a scenario framework combining alternative futures of climate and society to facilitate integrated research and consistent assessment to inform policy. Here we assess how well this framework is working and what challenges it faces. We synthesize insights from scenario-based literature, community discussions and recent experience in assessments, concluding that the framework has been widely adopted across research communities and is largely meeting immediate needs. However, some mixed successes and a changing policy and research landscape present key challenges, and we recommend several new directions for the development and use of this framework.

S cenarios have been a key component of global change research for four decades as a means of characterizing uncertainty in complex interacting human and environment systems. They are used to explore how the future may evolve under a range of alternative conditions, or how desirable outcomes might be achieved and undesirable outcomes avoided. They have played an important role in global change research by providing a small set of common climate change and societal futures for use across research communities.

Since 2010 (ref. ${ }^{1}$ ), multiple communities have collaborated on the so-called Shared Socioeconomic Pathway (SSP)-Representative Concentration Pathway (RCP) framework ${ }^{2-5}$ : a set of alternative socioeconomic development pathways (SSPs) and atmospheric concentration pathways (RCPs) with their associated climate change outcomes (Box 1).

The framework's primary goals are:

- To support climate change-related research globally across research communities and be extendable to other scales, sectors and issue areas;

- To facilitate research that integrates climate and societal futures by providing more detailed socioeconomic and political conditions as inputs to studies of impacts, adaptation and mitigation;

- To foster consideration of uncertainty in future climate and societal conditions by describing a wide range of plausible futures;

- To encourage more coherent synthesis in scientific assessments by improving the consistency of climate and societal assumptions in the literature; and

- To support research and analysis to inform policy.
The RCPs were published in 2011 (ref. ${ }^{6}$ ) and the SSPs in 2017 (ref. ${ }^{7}$ ), with elements available several years prior. Significant experience gained since then supports a first evaluation. A Scenarios Forum brought together more than 300 international participants in 2019 to discuss progress on scenario development and use, particularly focusing on the SSP-RCP framework ${ }^{8}$. We build on those discussions to evaluate successes, identify needs and recommend a number of modifications and directions for future work.

The SSP-RCP framework departs from previous approaches to climate change scenarios by developing climate and societal futures in parallel, and then combining them in integrated research (figure in Box 1). Both SSPs and RCPs are therefore incomplete by design, in that the RCPs generate climate projections that are not interpreted as corresponding to specific societal pathways, while the SSPs are alternative societal futures in which no climate change impacts occur, nor climate policy responses implemented. SSPs and RCPs are 'completed' when combined and applied in individual studies where climate risks and adaptation or mitigation strategies are assessed.

\section{Achievements}

Experience with the scenario framework indicates that it has successfully facilitated substantial progress toward achieving its original goals.

For example, the framework is supporting research across a wide range of topic areas and is being extended for use at a range of scales. The SSPs have been employed in more than 1,370 analyses related to climate change drivers, risks and response options (Fig. 1). Within

Pardee Center for International Futures, Josef Korbel School of International Studies, University of Denver, Denver, CO, USA. ${ }^{2}$ Finnish Environment Institute (SYKE), Helsinki, Finland. ${ }^{3}$ Center for Health and the Global Environment, University of Washington, Seattle, WA, USA. ${ }^{4}$ UK Centre of Ecology \& Hydrology, Lancaster, UK. ${ }^{5}$ Stockholm Environment Institute, Somerville, MA, USA. ${ }^{6}$ Wageningen University \& Research, Wageningen, the Netherlands. ${ }^{7}$ Potsdam Institute for Climate Impact Research (PIK), Member of the Leibniz Association, Potsdam, Germany. ${ }^{8}$ RAND Corporation, Santa Monica, CA, USA. 'International Institute for Applied Systems Analysis (IIASA), Laxenburg, Austria. ${ }^{10} \mathrm{Center}$ for International Climate Research (CICERO), Oslo, Norway. ${ }^{11}$ Netherland Environmental Assessment Agency (PBL), The Hague, the Netherlands. ${ }^{12}$ Copernicus Institute of Sustainable Development, Utrecht University, Utrecht, the Netherlands. ${ }^{13}$ Center of Atmospheric Sciences, National Autonomous University of Mexico (CCA-UNAM), Mexico City, Mexico. ${ }^{14}$ Ritsumeikan University, Kasuatsu, Japan. ${ }^{15}$ German Development Institute, Bonn, Germany. ${ }^{16}$ ClimateWorks Foundation, San Francisco, CA, USA. ${ }^{17}$ Centre for World Economy Studies (CIEM), Havana, Cuba. ${ }^{18}$ Present address: Joint Global Change Research Institute, Pacific Northwest National Laboratory, College Park, MD, USA. $\varpi_{e}$-mail: brian.oneill@pnnl.gov 


\section{Box 1 | The SSP-RCP scenario framework}

The SSPs and RCPs describe alternative visions of how society and climate may evolve over the coming decades, providing a framework for combining these pathways in integrated studies (Fig. 1) ${ }^{3}$.

The SSPs include societal factors such as demographics, human development (for example, health and education), economic growth, inequality, governance, technological change and policy orientations ${ }^{4,99}$. Most factors are given as narratives that sketch broad patterns of change globally and for large world regions ${ }^{72}$. A subset (population ${ }^{100}$, GDP ${ }^{101-103}$, urbanization ${ }^{104}$ and educational attainment ${ }^{100}$ ) are provided as quantitative, country-specific projections. These variables were chosen based on their common use as inputs to emissions or impact models and their relationships to each other. Education, for example, was used in projecting both population and GDP. These 'basic' SSPs provide core information to promote consistency across scenario-based studies, while extensions to finer scales and sectors were encouraged to expand the utility of the framework to a wider range of applications.

Five SSPs were developed to span a range of outcomes for two characteristics of society: the challenges that the underlying factors in each pathway present to adapting to climate change, and the challenges they present to mitigating climate change ${ }^{4,99}$. The SSPs do not include mitigation and adaptation responses themselves, nor do they include the impacts of climate change. This design choice was made so that integrated studies can assess the effects of policies or magnitude of impacts included in their own studies by comparing outcomes to those in the SSPs. This approach allows the SSPs to be used as a reference case for a large number of studies investigating a variety of policies and projected risks.

Motivated by the fact that a wide variety of approaches to mitigation or adaptation policy are possible, SPAs were developed that describe a smaller number of broad approaches to these policies ${ }^{5,7}$. Along with other policy assumptions, like radiative forcing or global warming targets, SPAs are intended to foster common approaches across studies and support more robust assessment of the mitigation and adaptation literature (Box 2).

Quantitative projections of energy use, emissions and land use based on the SSPs and SPAs were produced using IAMs ${ }^{7}$. SSP-based emission scenarios that do not include mitigation policy result in greenhouse gas concentrations by 2100 that are at the high end of the range covered by the RCPs. However, each SSP can be made consistent with lower levels of radiative forcing by adding assumptions about mitigation policy. The mitigation necessary to achieve a given forcing outcome in each SSP will differ according to its challenges to mitigation.

A selection of SSP-based IAM scenarios were used to drive Earth system models to project future climate change $e^{47,105}$. This new generation of climate projections is beginning to become available. However, integration of climate and societal futures did not need to wait for these SSP-based climate projections. Hundreds of studies have already combined the societal futures depicted in the SSPs with climate projections based on the RCPs. The RCPs are pathways of greenhouse gas concentrations over time that were based on emissions scenarios that pre-dated the SSPs (Fig. 1) ${ }^{6}$, and a first generation of climate model simulations already produced climate outcomes projected to result from the RCPs ${ }^{106}$. Using the SSPs and RCPs together is not inconsistent because it has been well established that many different societal pathways can produce approximately the same radiative forcing and climate change outcomes $^{73}$. The SSP-based climate projections will serve to update and extend the original RCPs.

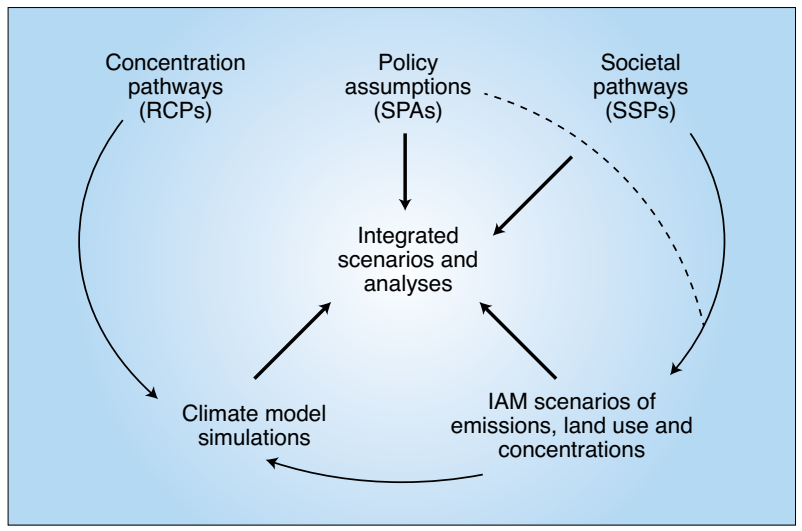

The scenario framework and process for producing integrated studies combining future climate outcomes, societal conditions and policy assumptions. A more detailed version of this figure separating successive generations of concentration pathways, climate model simulations and integrated studies is available in the Supplementary Information. impacts-related research, applications to agriculture, water (including hydrologic extremes) and health predominate, but smaller numbers of studies address topics as diverse as poverty, tourism, conflict, ecological impacts and economic growth. More than 70 of these studies address multiple topics equally.

The full set of SSP information is being employed, although not all elements of SSPs are used in every study. In many cases, studies draw on basic quantitative inputs such as population ( $>890$ papers) and gross domestic product (GDP) $(>780)$ pathways. A substantial number $(>580)$ draw on the narratives. Many use the urbanization $(>160)$ or education $(>60)$ projections. These new types of quantitative information relative to what previous scenarios provided enable analyses of new dimensions of future exposure and vulnerability to climate hazards, such as for urban health ${ }^{9}$ or for agriculture ${ }^{10}$.

The SSP narratives have proven useful for supporting a large number of extensions. For example, global narrative extensions were produced for key sectors to support quantitative projections from energy and land-use models, and projections from integrated assessment models (IAMs) ${ }^{11,12}$. The IAM scenarios, in turn, have been useful for a range of applications, such as highlighting the role of socioeconomic pathways in achieving stringent mitigation goals ${ }^{7,13}$.

Similarly, the population and GDP information in the basic SSPs has been enhanced by extending it to gridded population distributions ${ }^{14-17}$ and within-country income distributions ${ }^{18-20}$. These extensions have helped identify the scale and spatial patterns of expected exposure to various climate hazards ${ }^{21-24}$, inform spatial patterns of demand for land and other climate drivers, and support analyses of climate implications for poverty and the most vulnerable ${ }^{20,21}$.

Additional global extensions support analyses across a wide range of sectors, including air pollution ${ }^{25}$, health ${ }^{26}$, water ${ }^{27}$, forest management $^{28}$ and oceans ${ }^{29}$. Extensions to support analysis of violent conflict $^{30}$ and governance ${ }^{31}$ represent progress in topics that were previously under-served by scenarios. For instance, in one study that found large direct impacts of climate change on violent conflict to be unlikely, conflict propensity varied widely between SSP1 and SSP3 (ref. ${ }^{30}$ ). Projections of the climate change adaptive capacity of political systems using governance indicators show that even with optimistic assumptions (SSPs 1 and 5), it may take three decades to develop the capacity necessary to cope with projected climate risks ${ }^{31}$. 


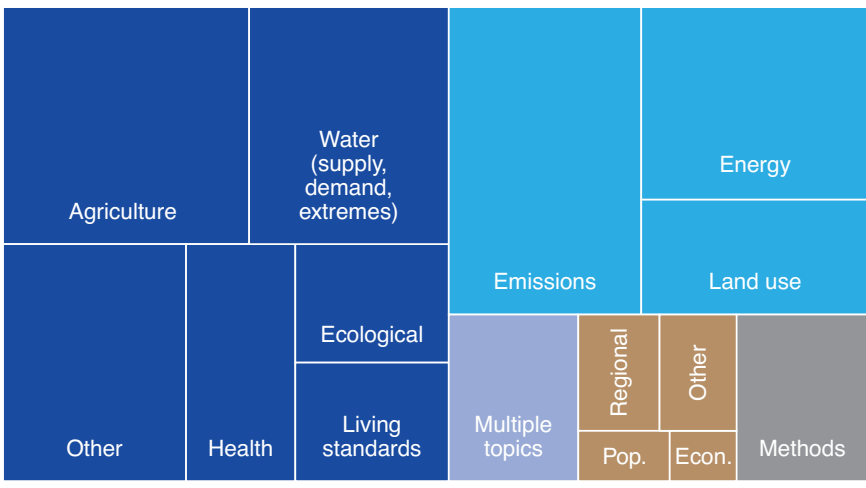

Fig. 1 | Application of SSPs by primary topic of analysis. Areas of rectangles are proportional to the number of studies in each category. Colours represent applications of SSPs (blue shading), scenario methods (light grey) and extensions of SSP information (light brown). Applications include those primarily on climate impacts or adaptation (dark blue), drivers or mitigation (light blue), or address multiple topics equally (medium blue). Results based on 1,378 analyses published 2014-2019 that use or develop SSPs and, in many cases, apply RCPs as well. We exclude papers that use RCPs only. See Supplementary Information for methods and definitions and ref. ${ }^{98}$ for data.

SSP extensions to regions have enabled their use across multiple time and spatial scales, diversifying types of users and research questions $^{32-35}$. For example, extensions of the SSPs were developed for Europe ${ }^{35}$ and used as context for developing SSPs for individual regions (Iberia, Hungary and Scotland) with local stakeholders. These regional SSPs were combined with downscaled climate scenarios based on two RCPs to serve as an input for a range of climate change impact models ${ }^{36}$ and as context for the development of adaptation and mitigation pathways with decision-makers ${ }^{37}$.

The goal for the framework of facilitating research that integrates climate and societal futures also appears to be well-served. In more than 700 studies, the SSPs were combined with RCPs to carry out integrated analysis. More than half of SSP-based studies are related to impacts, adaptation and vulnerability (Fig. 1), frequently concluding that societal development and choices can be the most significant drivers of climate-related risks in many sectors, including health ${ }^{9}$, food ${ }^{38}$, water ${ }^{39}$ and buildings ${ }^{40}$. As an example, projections of indicators of risk from different levels of global mean temperature change and socioeconomic development show that the number of people vulnerable to impacts in water, energy and land sectors is sensitive to both determinants $s^{21,36}$. Projected global exposure to multisector risks approximately doubles between $1.5^{\circ} \mathrm{C}$ and $2.0^{\circ} \mathrm{C}$, and doubles again with $3.0^{\circ} \mathrm{C}$ of warming above pre-industrial temperatures $^{21}$. For populations vulnerable to poverty, exposure is 8 - to 32-fold greater under SSP3 than SSP1.

Progress toward incorporating uncertainty into societal and climate futures is evidenced by the fact that the full range of SSPs and RCPs is being used (Fig. 2). Risks and response options are being investigated from high climate change outcomes (RCP8.5) to outcomes consistent with the Paris Agreement $1.5^{\circ} \mathrm{C}$ goal (RCP1.9) ${ }^{13}$, and from development pathways with high challenges to mitigation (SSPs 3 and 5) and adaptation (SSPs 3 and 4) to development pathways with low challenges to mitigation (SSPs 1 and 4) and adaptation (SSPs 1 and 5). Their use is uneven, however, and there are more studies based on the middle-of-the-road development pathway (SSP2, 30\%) and climate change outcomes available from existing Earth system model projections (RCPs 2.6, 4.5, 6.0 and 8.5 from Coupled Model Intercomparison Project 5 (CMIP5)), especially for the highest forcing pathway (RCP 8.5, 29\%; see Fig. 2). The balance of studies is likely to evolve over time, especially as new Earth

\section{Box 2 | Improving policy research with SPAs}

Policy research is facing a growing challenge: the literature is uncoordinated, investigating a wide variety of policies with few assumptions in common across studies. As a result, it is difficult to draw robust conclusions about specific policy approaches.

To address this challenge and improve the robustness of policy conclusions, we recommend further development and wider application of SPAs. SPAs are an integral component of the scenario framework (Box 1) describing key characteristics of mitigation and adaptation policies at the global scale, such as instruments and implementation obstacles, that are not included in the RCPs or SSPs ${ }^{5}$. They are motivated by the aim of fostering common assumptions across a large number of studies to provide structure to the policy literature and allow for stronger conclusions about important policy issues to be drawn. An initial set of mitigation SPAs generated SSP-based mitigation scenarios that led to a wide range of climate outcomes? ${ }^{7}$. These SPAs specified the degree of climate policy coordination between sectors and regions and how it could evolve over time. They were an important factor for the achievability of low warming targets in the SSP-RCP scenario framework ${ }^{7,13}$.

With more widespread adoption of climate policy plans around the world, the use of SPAs in mitigation pathway research can increasingly be coupled to actual climate policy developments. New SPAs could be developed for wide community use, including for the policy component of proposed new reference scenarios (see main text). These SPAs would aim to address specific policy issues, such as achieving the Paris Agreement goals or the implications of current or planned climate policies ${ }^{75}$. A continuous identification of new SPAs for policy scenarios would help the scenario framework stay up-to-date with the rapidly evolving policy landscape and thus keep it relevant for policy research.

The use of SPAs has been particularly limited for adaptation. Sharing common adaptation assumptions is challenging because adaptation policies are highly context-dependent, typically developed at a regional level and often co-produced with regional stakeholders ${ }^{107}$. Nonetheless, a concerted effort to develop regionally differentiated adaptation SPAs could help structure learning about alternative approaches to adaptation. For example, a set of four alternative SPAs for adaptation in river deltas in Africa and Asia helped explore the effectiveness of alternative response options across climate and societal futures ${ }^{65}$.

system model simulations become available (CMIP6) for a fuller range of forcing pathways.

Finally, regarding the goal of encouraging more coherent scientific assessments, the scenario framework has been widely used in key environmental assessment reports, including three Intergovernmental Panel on Climate Change (IPCC) special reports ${ }^{41-43}$, the global report from the Intergovernmental Science-Policy Platform on Biodiversity and Ecosystem Services $(\mathrm{IPBES})^{44}$, and other global assessments ${ }^{45,46}$.

For example, in the IPCC Special Report on Global Warming of $1.5^{\circ} \mathrm{C}$ (ref. ${ }^{41}$ ), the framework was used across the report to consider alternative pathways consistent with the $1.5^{\circ} \mathrm{C}$ target, leading to several key conclusions: that mitigation and adaptation options have many synergies with sustainable development; that pathways characterized by inequality, poverty and lack of international cooperation may not be able to meet the goal; and that low-demand pathways would reduce the reliance on energy technologies that have potential negative consequences for food security and biodiversity. 


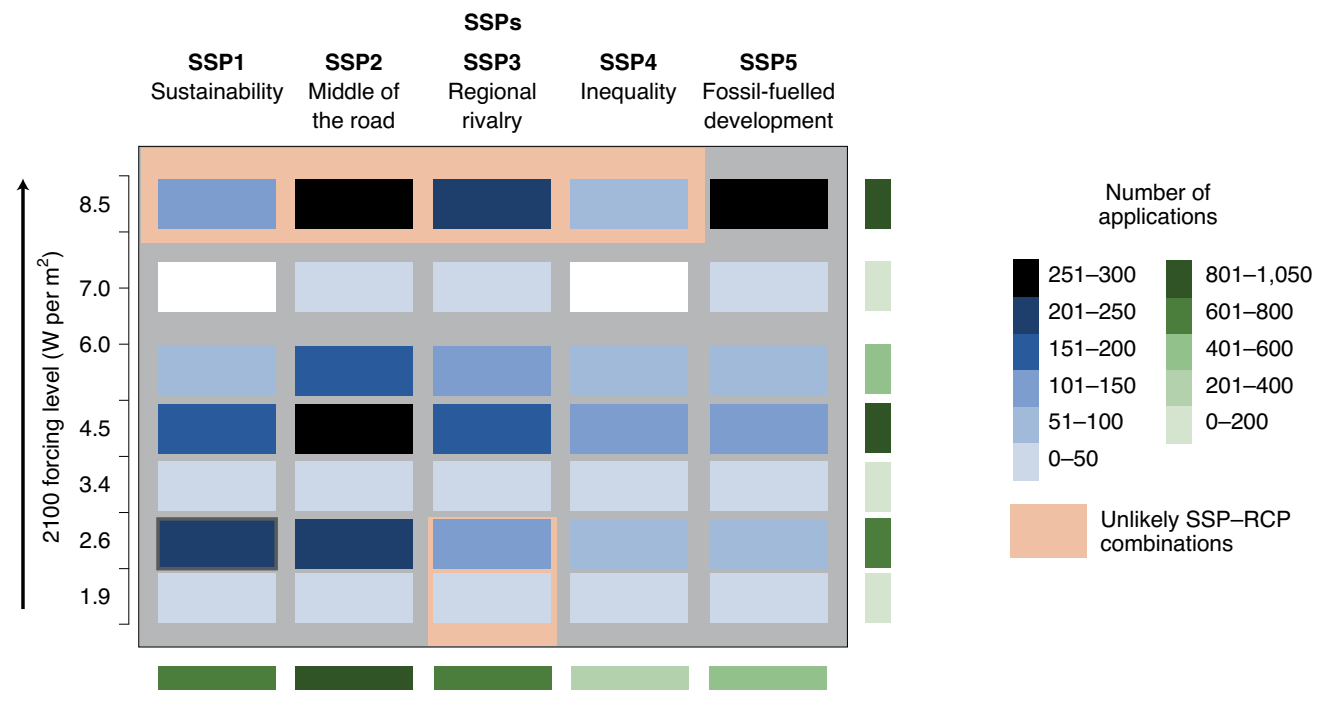

Fig. 2 | Numbers of applications of SSP-RCP combinations in 715 total studies applying integrated scenarios, published over the period $2014-2019$. Each cell represents an SSP-RCP combination, with colours indicating the number of applications. White cells indicate no applications. Green rectangles along the right side of the figure indicate totals for each RCP (rows); those along the bottom of the figure indicate totals for each SSP (columns). Unlikely SSP-RCP combinations indicate those in which integrated assessment models found the outcomes infeasible under the SSPs and SPAs assumed ${ }^{7 / 13}$. Forcing levels labelled on the vertical axis are not spaced in exact correspondence to tick marks to improve clarity of the figure. RCP6.0 reaches approximately $5.5 \mathrm{~W}$ per $\mathrm{m}^{2}$ forcing in 2100 . See Supplementary Information for methods and ref. ${ }^{98}$ for data.

The IPCC Special Report on Climate Change and Land ${ }^{42}$ used SSP-based literature to conclude that risks related to desertification, land degradation and food insecurity are strongly determined by socioeconomic conditions, not just the level of global temperature increase.

The SSPs also provided the basis for the emissions and land-use scenarios currently used by climate models that will project climate outcomes for the IPCC's sixth assessment report ${ }^{47}$, and efforts are ongoing to coordinate the use of scenarios across the three working groups ${ }^{8}$.

The IPBES global and four regional assessment reports mapped the SSP-RCP framework to a set of scenario archetypes to synthesize risks from climate and societal drivers on biodiversity and ecosystem services ${ }^{48}$. A key conclusion from the global assessment was that risks to biodiversity and nature's contributions to people were lowest under the 'global sustainability' scenario (based on SSP1-2.6, where the second number indicates the RCP), while the 'economic optimism' scenario (based on SSP5-8.5) resulted in the largest number of trade-offs between biodiversity and different contributions of nature to people.

Needs and recommendations. Alongside these successes, opportunities for increasing the usefulness and relevance of the framework were identified. We highlight the most important issues and offer recommendations for addressing each issue (summarized in Table 1).

\section{Improve integration of societal and climate conditions}

Policy- and decision-makers charged with preparing for and managing the risks of a changing climate need improved integrated studies that provide more targeted support for assessing response options. For example, few integrated studies assess resilience (the ability to cope with and recover from climate-related losses), and many adaptation scenario studies simply state the kind of adaptation actions that are assumed to occur rather than articulating the transitions by which adaptation outcomes are achieved ${ }^{10,49-51}$. In addition, while gradual changes in climate are important, improved information is needed on possibly unlikely but highly consequential changes in extreme events.
Understanding future resilience would be improved by projections not only of traditional consumption-based poverty levels, but also of social protection, financial inclusion, strength of governance and political institutions, retirement funds and health care access, particularly on sub-national scales. The development of adaptation transitions would be supported by extending the SSPs to include quantified indicators of vulnerability and resilience, and consideration of the potential for societal tipping points that might hasten, or impede, transitions ${ }^{52}$. Initial progress on projections of governance $^{31}$ and violent conflict ${ }^{30}$ should be broadened to include political institutions and integrated into the SSPs.

To improve the consideration of extreme events, narrative descriptions of future climate events or trends could be added to scenarios that focus on low-likelihood but potentially high-risk outcomes for society. This 'physical climate storyline' approach ${ }^{53,54}$ describes how the impact of current weather events may change in the future due to unprecedented combinations of climate and societal conditions $\mathrm{s}^{55}$, helping us to understand complex interactions between the physical, ecological, economic and societal aspects of extreme or compound events ${ }^{56}$. Physical climate storylines can be usefully combined with the SSP-RCP framework as part of downscaling to regional and local scales ${ }^{57}$.

Information on climate and societal conditions is needed at scales relevant for decision-making. To address this need, downscaled climate projections at regional and local scales ${ }^{58}$ should be made more consistent with projected societal trends. For example, given the implications of land-use change for regional climate and variations in land use across SSPs, some regional activities are already planning SSP-specific downscaling of climate change outcomes; more should be pursued. Furthermore, there are added complexities involved in specifying consistent future conditions for considering impacts locally that propagate across borders or other socioeconomic domains ${ }^{59}$.

Finally, when integrating climate and societal futures, the plausibility of particular combinations should be carefully considered. A number of models found that the radiative forcing levels in RCP8.5 can be achieved only by SSP5 (ref. ${ }^{7}$ ), and that the forcing levels in RCPs 1.9 and 2.6 are not achievable under SSP3 (ref. ${ }^{13}$ ). 
Table 1 | Summary of recommendations for improving the SSP-RCP framework and the issues each would benefit

\begin{tabular}{|c|c|c|c|c|c|c|c|}
\hline \multirow[b]{2}{*}{ Recommendations } & \multicolumn{7}{|c|}{ Scenario framework needs } \\
\hline & $\begin{array}{l}\text { Improve } \\
\text { climate/ societal } \\
\text { integration }\end{array}$ & $\begin{array}{l}\text { Improve } \\
\text { regional } \\
\text { applicability }\end{array}$ & $\begin{array}{l}\text { Improve } \\
\text { relevance beyond } \\
\text { climate }\end{array}$ & $\begin{array}{l}\text { Improve use in } \\
\text { policy research }\end{array}$ & $\begin{array}{l}\text { Capture relevant } \\
\text { perspectives }\end{array}$ & $\begin{array}{l}\text { Keep } \\
\text { scenarios up } \\
\text { to date }\end{array}$ & $\begin{array}{l}\text { Improve } \\
\text { relevance } \\
\text { for users }\end{array}$ \\
\hline
\end{tabular}

Modify current framework

Extend SSPs to include additional quantified indicators of vulnerability and resilience

Integrate physical climate storylines into framework

Extend the framework to support adaptation pathway development

Extend the SSP narratives to cover key international societal and environmental goals, such as the SDGs and CBD targets

Improve scenario development process

Connect the SSP-RCP framework to parallel scenario activities using scenario archetypes

Define and promote the use of SPAs for both mitigation and adaptation

Make the scenario development process as inclusive as possible

Establish a process for regular updates of the scenario framework

\section{Connect to users and other research communities}

Develop community consensus on methods + for working with SSPs across scales

Develop sanctioned regional scenarios that + can be used across organizations

Raise awareness of the relevance of the SSPs to societal objectives beyond climate change by widely demonstrating how they can be restructured on alternative axes

Develop guidance materials and online repositories to foster interdisciplinary collaboration and capacity building

Create 'climate change scenario services' to cater to needs of users

\section{New research}

Develop improved regional climate information

Develop a more diverse set of global SSPs as boundary conditions for multi-scale analyses

Consider how scenarios can best account for future shocks

Develop new reference scenarios including relevant climate policies and impacts

Better understand needs for sustainable development policy analysis

Evaluate uncertainty range covered by framework and possible missing futures

Consider alternative methods, techniques and processes to cover relevant futures and ensure legitimacy

Tick marks indicate recommendations made to address the issue in the indicated column; + signs indicate benefits to additional issues. 
Figure 2 indicates that many studies employed SSP-RCP combinations that may therefore be considered unlikely. Often these studies use scenario information in limited ways that lessen concerns about inconsistency, such as focusing on short-term outcomes ${ }^{60}$ or single elements of the SSPs (such as GDP or population growth), or use SSPs as sensitivity analyses. In other cases, greater care in combining assumptions will improve the relevance of results. It may be useful to develop indicators of consistency with the SSP-RCP framework that can be used in assessing the literature.

\section{Improve applicability to regional and local scales}

SSP applications to regional and local scales have generated a growing diversity of perspectives, methods and users, including practitioners working in climate adaptation, community resilience and sustainable development. A current challenge is how to maintain consistency across the growing richness of multi-scale SSP scenarios in terms of socioeconomic assumptions and trajectories ${ }^{61,62}$. Such consistency ultimately helps to increase the validity of global and regional SSP applications, and it is particularly desirable when comparing, combining or upscaling regional applications of the SSPs.

At present, there is no commonly agreed best practice regarding methods for downscaling the global SSPs. Rather, alternative methods and experiments have emerged organically in a relatively ad hoc manner. For example, scenarios have been developed locally in a participatory manner and then mapped to, or contextualized with, the global SSPs ${ }^{63-65}$. Alternatively, the SSPs have been used to stress test bottom-up, normative scenarios and strategies ${ }^{66}$. While such studies reflect the flexibility of the SSP framework, that flexibility also hinders the development of reproducible approaches to downscaling.

What is now needed are credible, reproducible and consistent methods for the use of the SSPs across scales to pursue new questions and needs. We recommend three actions. First, a more diverse set of global SSPs should be developed to enable the exploration of a broader set of boundary conditions for multi-scale analyses (see the 'Capture relevant perspectives and uncertainties' section below for examples). This could include development of SSP variants or the mapping of other scenarios or scenario families to the SSP framework based on common affinities or archetypes ${ }^{67,68,69}$. Second, community consensus should be developed around methods for working with the SSPs across scales. Convening researchers to learn from and evaluate the pool of approaches to develop more refined methods would be productive. Third, the development of sanctioned regional scenarios would facilitate consistency across different research endeavours and organizations. For example, for the Fourth U.S. National Climate Assessment ${ }^{70}$, a set of scenario products was developed based on the RCPs and SSPs to promote consistent use of scenario assumptions across sectoral and regional aspects of the assessment.

\section{Improve relevance beyond the climate research community} Application of the scenario framework to research domains beyond climate change has been limited, partly due to lack of relevant content. For example, the SSP-RCP scenarios were used in the IPBES Global Assessment but were found to lack information on the relationship between nature and people ${ }^{48}$. IPBES is therefore currently developing its own Natures Futures Framework ${ }^{71}$. Similarly, the World in 2050 (TWI2050) ${ }^{45}$, a community initiative on the Sustainable Development Goals (SDGs), used SSP1 (sustainability) as a starting point for its assessment but found no scenarios that were able to achieve all the SDGs simultaneously.

Broader use of the SSP-RCP framework would increase comparability of assessments across issues and help develop a more comprehensive view of possible integrated futures and response options. Four recommendations would facilitate this wider use. First, the SSPs should be mapped to assumptions about key drivers of economic, environmental and societal sustainability ${ }^{72}$. Second, the SSP narratives need to be extended to be able to inform analyses of how to meet key international societal and environmental goals beyond the Paris Agreement, such as those embodied in the 2030 Agenda for Sustainable Development and the Convention on Biological Diversity. These extensions should incorporate narratives relating to such targets, conditions under which synergies or trade-offs across policy domains would dominate, and information on barriers or enabling conditions such as the quality of governance and political institutions.

Third, parallel scenario activities such as the IPBES, TWI2050 and the SSPs should be connected by mapping scenarios onto each other using scenario archetypes ${ }^{73}$. Where key disconnects are identified, SSPs should be broadened to cover a wider range of worldviews or perspectives (for example, scenarios where all the SDGs are met). Fourth, guidance materials and online repositories are needed to foster interdisciplinary collaboration, learning and capacity building on scenarios across research communities. There is a particular need for social sciences to inform scenarios on societal dynamics and tipping points. In turn, social scientists should be aware that engaging with scenarios advances theory building and generalization in their own disciplines.

\section{Produce a broader range of reference scenarios that include impacts and policy}

A typical approach to model-based scenario analysis is to estimate the effects of introducing a feature of interest by comparing the results of two scenarios: a reference scenario that does not include the feature, and an alternative scenario that does. The feature of interest can be a policy (mitigation or adaptation), an alternative assumption about a driver (for example, population growth or effectiveness of governance) or a climate change impact (for example, climate effects on crop yield).

The scenario framework highlights five scenarios as reference cases (sometimes referred to as baseline scenarios): the no-policy and no-climate-impacts reference scenarios represented by the five SSPs. Yet there are a growing number of studies that require reference scenarios that include policies and/or impacts. These types of reference scenarios are useful when studying issues beyond climate change, including the relationship between climate change and sustainable development or air quality. They are also useful within climate research when studying impacts or policies in relation to other impacts or policies. That includes, for example, studies of climate policies beyond those currently implemented, which require comparison against a reference scenario of current policy trends. It also includes studies of particular impacts, such as conflict, that depend on a reference scenario representing other impacts, such as food and water security, that may co-determine the outcome of interest. Similarly, analyses of the costs and benefits of mitigation or adaptation policies require comparing climate change impacts with and without the implementation of mitigation policies. In addition, although no-policy and no-climate-impact reference scenarios have an important role in the scenario framework design (Box 1), stakeholders often find them unrealistic, which can hinder participatory scenario studies, policy dialogues and public acceptance.

We recommend producing a broader range of integrated reference scenarios within the existing scenario framework. The broader set would include new 'policy reference scenarios' based on current policy trends or assuming moderate levels of climate action ${ }^{74}$. A starting point is provided by individual studies that have begun developing new reference scenarios that, for example, extrapolate implemented and planned national climate policies into the future, or that achieve the Paris Agreement's nationally determined contributions (NDCs) to emissions reductions ${ }^{75}$. Such reference scenarios can be defined by combinations of SSPs and a set of shared reference policy assumptions (reference SPAs) in the SSP-RCP framework (see Box 2). 
It would also include reference scenarios with climate impacts based on a subset of existing SSP-RCP scenarios. A number of questions need to be addressed about how to develop such scenarios, including which impacts to include, how to represent uncertainty in outcomes and how both policies and impacts could be most effectively combined. It would also be crucial that the purpose of such reference scenarios be clearly labelled to preclude their adoption in analyses that lead to possible double counting of impact outcomes.

Integrated reference scenarios may also be critical to extend the application of the SSP-RCP framework to sustainable development research. We recommend conducting research on the characteristics of useful reference scenarios for the analysis of sustainable development pathways and how they could be connected to the existing scenario framework ${ }^{76}$. The distinction between SSPs (including development aspects and policies but no climate policies) and SPAs (including only climate policies) will become less useful in a sustainable development context. There is a need to identify SSP-SPA combinations that are tailored to the analysis of sustainable development policies.

\section{Capture relevant perspectives and uncertainties}

The scenario framework aims to capture a wide range of uncertainties and a broad set of perspectives with a manageable number of alternative futures. It is important to comprehensively cover futures that would be most relevant for societies to consider while excluding those that do not merit broad use. Relevant scenarios explore a range of plausible but widely different societal futures as well as futures considered desirable by some societal actors. For example, futures with no or limited growth in high-income countries or scenarios oriented around eco-communalism ${ }^{77}$ are not represented in the SSPs. Plausible futures that may be under-represented include those driven by disruptive events (Box 3), whether technological, social, political or environmental. For example, it may be useful to explore the implications of violent conflicts ${ }^{78}$, the crossing of biophysical and social tipping points or unexpectedly rapid technological innovation; for example, in artificial intelligence or energy efficiency ${ }^{79}$.

Addressing these issues will require careful attention to the process of choosing and developing new scenarios as well as to the range of plausible futures covered by existing scenarios. We recommend a continuous re-evaluation of the current range of uncertainties in SSPs, RCPs and their combinations. As trends in society, economy, energy systems, land use and emissions evolve over time, it is important to periodically check whether the range encompassed by the framework is too wide in some areas or too narrow in others. This process should involve assessing the potential for high emissions futures, including re-examining the assumptions underlying SSP5-8.5 (the highest forcing scenario in the current framework) in light of recent trends in energy systems. It should also involve further assessment of the plausibility of low emissions futures and the mitigation measures that might achieve them. Many IAM scenarios limiting warming to $1.5-2{ }^{\circ} \mathrm{C}$ make extensive use of carbon dioxide removal (CDR) technologies and bioenergy, approaches with potentially significant risks for ecosystems and agriculture. In response to criticism about this reliance on CDR, scenario research is exploring a variety of alternative mitigation strategies ${ }^{79,80}$ that explicitly limit CDR as well as carbon capture and storage technologies. It is important to continue to analyse alternative scenarios capturing a range of fundamentally different perspectives on technology and consumption futures, including nature-based solutions, deep lifestyle changes, a shift toward a circular economy, and techno-fixes like solar radiation management.

We also recommend that the process of scenario development be as inclusive as possible to capture a diverse set of perspectives from different parts of the world and different societal groups.
Inclusiveness can be fostered by making the framework and related scenario products more widely known and accessible, and by expanding participation through regional workshops and applications. Scenario products themselves should include greater regional heterogeneity, especially in developing country regions, to better represent diverse perspectives and conditions.

A more inclusive process would also improve the relevance and credibility of the scenarios to a wider range of researchers, users and stakeholders. The legitimacy ${ }^{81}$ of the choice of scenarios engendered by such a process is critical for scenario applications because they structure discourse and could generate self-fulfilling prophecies ${ }^{82}$. Pitfalls can be avoided by approaching the science-society interface in an iterative way to co-produce societally relevant and legitimate knowledge ${ }^{83,84}$. Critical reflection on implicit assumptions about the perspectives of decision-makers could improve the relevance of scenarios to a wider set of communities and cultures ${ }^{85,86}$. 'Layered methods ${ }^{87,88}$ could be used to expand the cultural breadth of climate change-related scenarios.

Exploring methods that move beyond the traditional two-axis scenario archetype to a richer and more systematically grounded set of scenarios might improve confidence in having a sufficiently wide and diverse scenario set. These methods can include scenario discovery approaches ${ }^{89,90}$ and semi-quantitative techniques for constructing scenarios that achieve specified goals, such as consistency, diversity or resilience ${ }^{91}$.

\section{Keep scenarios up to date}

The scenario framework was designed to support research over a sustained period of time. However, inconsistencies can develop between the framework and changing societal conditions, advancing knowledge and an evolving policy landscape. For example, the starting year of the quantitative drivers of the SSPs was 2010 (and for emissions was 2015), in some cases based on data from an earlier point in time. Updated data on national level GDP, fertility and mortality rates, and urbanization are available, and outlooks for near-term trends in energy systems and emissions have changed over time.

Updating the framework with recent data and trends will improve its perceived validity and suitability for research applications, especially those focused on near-term issues such as attainment of the NDCs. However, there is an inherent tension between revisions and providing a stable set of scenario information that promotes consistency in assumptions across the scientific literature. The COVID-19 crisis is a further complication, given the large uncertainty surrounding short-term recovery rates and their long-term implications (Box 3).

We recommend establishing a process for regular updates of the SSPs, and the emissions and land-use scenarios based on them, that balances stability and keeping up to date. Some elements of the framework have a higher priority for more frequent updates than others. Quantitative drivers, and the IAM scenarios based on them, should be updated frequently (at least every five years), with a focus on base-year data and near-term trends. We recommend that drivers be updated now to be consistent with new historical data. At the same time, individual IAM studies might explore implications of these updates and alternative possible COVID-19 futures. New community IAM scenarios that are part of the scenario framework and include the effects of the pandemic could be developed after the initial uncertainty about the pandemic's consequences lessens.

The overall narratives and framework could be more stable. As broader, qualitative descriptions of long-term alternative futures, they are less susceptible to changing conditions in the near term and would likely be modified, or new narratives added, for reasons of clarification or to represent new types of societal futures that become relevant to research or policy (see the 'Capture relevant perspectives and uncertainties' section). 


\section{Box 3 | Scenarios and COVID-19}

Global shocks such as pandemics, technological breakthroughs, economic crises and other natural or human-made disruptions (so-called 'wildcards') are irregular but expected features of socioeconomic development and, therefore, of scenarios. Some scenarios explicitly introduce such features ${ }^{108}$, while in others, including the SSP-RCP framework, they are implicit possibilities within narratives that sketch broader changes in society without specifying causal events.

The implications of the COVID-19 pandemic for the SSPs will depend on which of three possible types of consequences it has on societies worldwide. First, it may have primarily short-term impacts, with a V-shaped recovery, at least at a global, aggregate level. For example, if reductions in emissions in the first several months of the pandemic fade over the following months, global carbon dioxide emissions in 2020 would decline only $4-7 \%$ from the previous year ${ }^{109}$, with little long-term effect on global surface temperature ${ }^{110,111}$. The Great Recession of 2008 had a similarly temporary effect on global emissions. Viewed on a century timescale, even such potentially transformational wildcard events as the breakup of the Soviet Union and its associated geopolitical realignment had only a transitory impact on global economic growth.

The second possibility is that the indirect effects of the pandemic have longer-term consequences that positively or negatively modify the current development path but do not fundamentally change it. If the new development trajectory remains within the wide range of pathways already captured by the SSPs, modifications to the framework will not be necessary. For example, the pandemic could lead to a persistent reduction in economic growth rates (an L-shaped recovery), exacerbate inequalities and increase societal and political conflict. The very different responses by countries around the world could accelerate global power shifts and deepen inequalities across countries. Such consequences would move the world toward SSP4, characterized by a small number of globally connected elites with access to basic services and increasing numbers of poor and marginalized people who struggle with hunger and unemployment. Alternatively, the pandemic could trigger investments in health and education, lead to efforts to reduce inequality, increase investments in fair

RCPs are currently updated on a schedule dictated by the pace of climate model development and scientific climate assessments. If SSPs are updated more frequently than RCPs, as we propose, there will be inconsistencies between the latest version of the SSPs (and emissions and land-use scenarios based on them) and the versions used to drive RCP simulations. However, these inconsistencies are unlikely to be large enough to make the combined use of RCPs and SSPs invalid, especially for lower RCPs that strongly constrain emissions scenarios to meet forcing targets. Clear versioning of SSPs and RCPs will improve transparency about which sets of assumptions are being used in a particular study.

\section{Improve relevance of climate change scenario applications for users}

The number of users of climate change scenario information has increased substantially over recent years, but the availability of information tailored to specific needs has not kept pace ${ }^{92}$. Users now extend beyond policymakers and planning authorities to include businesses looking to evaluate the alignment of investment decisions with the Paris climate goals and the finance sector, which has become increasingly interested in assessing climate-related financial risk ${ }^{93,94}$. Subnational actors (for example, cities) and civil society are also turning to scenarios to help inform their climate resilience strategies ${ }^{95}$. digitalization, reduce travel and use of fossil fuels, and reduce environmental impacts. Consequences like these could shift the development pathway toward SSP1.

A third possibility is that COVID-19 contributes to the crossing of a tipping point in human and natural systems, shifting development pathways to a fundamentally new trajectory ${ }^{112}$. The inequalities highlighted by the pandemic may be a route to such transformational change. Societal resistance, whether peaceful or violent, has been common during periods with high levels of inequalities ${ }^{113}$. Societal conflicts were the starting point of most great transformations; structural changes resulted in new policies and programmes to increase societal equity and improve development pathways ${ }^{114}$. In this way, disruptions can lead to discontinuities in development pathways ${ }^{115}$. Whether such an outcome would require changes to the SSP framework is less clear, because even some transformational changes might remain within the very wide range of challenges to mitigation and adaptation spanned by the SSPs. A broader research programme could explore the SSP space beyond the current narratives by, for example, identifying 'weak signals' of currently niche phenomena that could dominate in an alternative future ${ }^{116}$.

A recent SSP-based stakeholder exercise, held after the start of the pandemic, illustrates the framework's continuing relevance. In May 2020, stakeholders from academia, policy, practice and business downscaled and enriched versions of the SSPs for the UK and its countries ${ }^{117}$. The SSP framework was deemed sufficiently flexible to enable participants to frame the issues that COVID-19 raised. For instance, one key element considered was 'Response to global shocks', framed between the extremes of 'persistence' and 'transformative change', while a second element was 'Health', framed in terms of low versus high investment. Stakeholders included COVID-19-related concerns into the development of the UK SSPs.

The SSP-RCP framework continues to be relevant and is consistent with wildcard events, but monitoring the consequences of COVID-19 and ensuring that scenarios continue to be flexible to account for future shocks will be important for deciding if and when revisions are necessary.

To meet these increasingly diverse needs, we propose the creation of 'climate change scenario services' analogous to the rapidly developing area of 'climate services ${ }^{96}$ that brings climate change projections to users. First, capacity building is needed to allow users to better understand climate change scenario approaches and the SSP-RCP framework. Second, communication of scenario results should be improved through novel approaches including infographics, cartoons or illustrations of simplified system dynamics and climate or integrated assessment models (for example, climatescenarios.org). Third, easy access to climate change scenario products should be provided, for example, through portals tailored to user needs and capabilities. It would be particularly useful to develop a user-friendly online database containing all relevant information about the SSP-RCP scenarios, including narratives, extensions, variants and downscaling products. Fourth, stakeholders should be involved in the co-production of scenario knowledge to improve its usefulness and create ownership.

\section{Looking ahead}

The climate change scenario framework, like previous generations of scenarios and those developed for other research communities, is intended to benefit an array of researchers, users and assessment processes. To ensure the framework's ongoing value, the scenarios 
community should not only learn from the successes, shortcomings and ongoing challenges, but also act on such lessons. The 20 proposed recommendations (Table 1) provide a starting point for such actions. They include modifications to the current framework, improvements to the scenario development process, ways to better connect to users and other research communities, and new research to be carried out to investigate open questions.

Over time, further aspects of the framework will need to be considered. There are inherent tensions in fostering both the use of common assumptions and the application to a wide diversity of sectors, regions and stakeholders. The approach of distinguishing 'basic' and 'extended' SSPs for this purpose will have to be revisited over time. Likewise, the specification of mitigation scenarios through the use of RCPs based on radiative forcing is not always consistent with the desire to evaluate outcomes associated with peak or long-term average global warming ${ }^{97}$. Investigating alternative framings would be desirable.

To foster and track progress, and revise goals as experience accumulates, the Scenarios Forum is intended to become a regular biennial event ${ }^{8}$, with researchers communicating in the meantime via a dedicated organization (www.iconics-ssp.org) for maintaining close ties across relevant research communities. Wide participation in the development, use and continuous re-evaluation of the scenario framework will ensure its continuing utility to the global change community.

Received: 16 November 2019; Accepted: 15 October 2020; Published online: 25 November 2020

\section{References}

1. Moss, R. H. et al. The next generation of scenarios for climate change research and assessment. Nature 463, 747 (2010).

2. Ebi, K. L. et al. A new scenario framework for climate change research: background, process, and future directions. Climatic Change 122, 363-372 (2014).

3. van Vuuren, D. P. et al. A new scenario framework for climate change research: scenario matrix architecture. Climatic Change 122, 373-386 (2014).

4. O’Neill, B. C. et al. A new scenario framework for climate change research: the concept of shared socioeconomic pathways. Climatic Change 122, 387-400 (2014).

5. Kriegler, E. et al. A new scenario framework for climate change research: the concept of shared climate policy assumptions. Climatic Change 122, 401-414 (2014).

6. van Vuuren, D. P. et al. The representative concentration pathways: an overview. Climatic Change 109, 5 (2011).

7. Riahi, K. et al. The Shared Socioeconomic Pathways and their energy, land use, and greenhouse gas emissions implications: an overview. Glob. Environ. Change 42, 153-168 (2017).

A synthesis of the SSP narratives, quantitative elements and integrated assessment model scenarios of energy, land use and emissions.

8. O'Neill, B. C. \& Scientific Steering Committee. Forum on Scenarios of Climate and Societal Futures: Meeting Report (University of Denver, 2019); https://pardee.du.edu/forum-scenarios-climate-and-societal-futuresmeeting-report

Documents the wide variety of topics being addressed by a growing and diverse community developing and using scenarios.

9. Chowdhury, S., Dey, S. \& Smith, K. R. Ambient PM 2.5 exposure and expected premature mortality to 2100 in India under climate change scenarios. Nat. Commun. 9, 318 (2018).

10. Williges, K., Mechler, R., Bowyer, P. \& Balkovic, J. Towards an assessment of adaptive capacity of the European agricultural sector to droughts. Clim. Serv. 7, 47-63 (2017).

11. Bauer, N. et al. Shared Socio-economic Pathways of the energy sector - quantifying the narratives. Glob. Environ. Change 42, 316-330 (2017).

12. Popp, A. et al. Land-use futures in the shared socio-economic pathways Glob. Environ. Change 42, 331-345 (2017).

13. Rogelj, J. et al. Scenarios towards limiting global mean temperature increase below $1.5^{\circ} \mathrm{C}$. Nat. Clim. Change 8, 325-332 (2018).

14. Jones, B. \& O’Neill, B. C. Spatially explicit global population scenarios consistent with the Shared Socioeconomic Pathways. Environ. Res. Lett. 11, 084003 (2016)
15. Merkens, J.-L., Reimann, L., Hinkel, J. \& Vafeidis, A. T. Gridded population projections for the coastal zone under the Shared Socioeconomic Pathways. Glob. Planet. Change 145, 57-66 (2016).

16. Terama, E., Clarke, E., Rounsevell, M. D. A., Fronzek, S. \& Carter, T. R. Modelling population structure in the context of urban land use change in Europe. Reg. Environ. Change 19, 667-677 (2019).

17. Wear, D. N. \& Prestemon, J. P. Spatiotemporal downscaling of global population and income scenarios for the United States. PLOS ONE 14, e0219242 (2019)

18. Rao, N. D., Sauer, P., Gidden, M. \& Riahi, K. Income inequality projections for the Shared Socioeconomic Pathways (SSPs). Futures 105, 27-39 (2018).

19. Van der Mensbrugghe, D. Shared Socio-economic pathways and global income distribution. In 18th Annual Conference on Global Economic Analysis (GTAP, 2015).

20. Hallegatte, S. \& Rozenberg, J. Climate change through a poverty lens. Nat. Clim. Change 7, 250-256 (2017).

21. Byers, E. et al. Global exposure and vulnerability to multi-sector development and climate change hotspots. Environ. Res. Lett. 13, 055012 (2018). Integrates a variety of climate and societal information to identify locations of high exposure and vulnerability.

22. Jones, B., Tebaldi, C., O’Neill, B. C., Oleson, K. \& Gao, J. Avoiding population exposure to heat-related extremes: demographic change vs climate change. Climatic Change 146, 423-437 (2018).

23. Harrington, L. J. \& Otto, F. E. L. Changing population dynamics and uneven temperature emergence combine to exacerbate regional exposure to heat extremes under $1.5^{\circ} \mathrm{C}$ and $2{ }^{\circ} \mathrm{C}$ of warming. Environ. Res. Lett. 13, 034011 (2018)

24. Rohat, G. et al. Influence of changes in socioeconomic and climatic conditions on future heat-related health challenges in Europe. Glob. Planet. Change 172, 45-59 (2019).

25. Rao, S. et al. Future air pollution in the Shared Socio-economic Pathways. Glob. Environ. Change 42, 346-358 (2017).

26. Ebi, K. Health in the new scenarios for climate change research. Int. J. Env. Res. Pub. He. 11, 30-46 (2013).

27. Graham, N. T. et al. Water sector assumptions for the Shared Socioeconomic Pathways in an integrated modeling framework. Water Resour. Res. 54, 6423-6440 (2018)

28. Kemp-Benedict, E., de Jong, W. \& Pacheco, P. In Forests Under Pressure, Local Responses to Global Issues (eds Katila, P. et al.) 539-553 (IUFRO, 2014).

29. Maury, O. et al. From Shared Socio-economic Pathways (SSPs) to oceanic system pathways (OSPs): building policy-relevant scenarios for global oceanic ecosystems and fisheries. Glob. Environ. Change 45, 203-216 (2017).

30. Hegre, H. et al. Forecasting civil conflict along the shared socioeconomic pathways. Environ. Res. Lett. 11, 054002 (2016).

31. Andrijevic, M., Cuaresma, J. C., Muttarak, R. \& Schleussner, C.-F. Governance in socioeconomic pathways and its role for future adaptive capacity. Nat. Sustain. 3, 35-41 (2020).

Extends the SSPs with projections of governance to facilitate integrated studies.

32. Absar, S. M. \& Preston, B. L. Extending the Shared Socioeconomic Pathways for sub-national impacts, adaptation, and vulnerability studies. Glob. Environ. Change 33, 83-96 (2015).

33. Rohat, G., Flacke, J., Dao, H. \& van Maarseveen, M. Co-use of existing scenario sets to extend and quantify the shared socioeconomic pathways. Climatic Change 151, 619-636 (2018).

34. McManamay, R. A., DeRolph, C. R., Surendran-Nair, S. \& Allen-Dumas, M. Spatially explicit land-energy-water future scenarios for cities: guiding infrastructure transitions for urban sustainability. Renew. Sust. Energ. Rev. 112, 880-900 (2019).

35. Kok, K., Pedde, S., Gramberger, M., Harrison, P. A. \& Holman, I. P. New European socio-economic scenarios for climate change research: operationalising concepts to extend the shared socio-economic pathways. Reg. Environ. Change 19, 643-654 (2019).

36. Harrison, P. A. et al. Differences between low-end and high-end climate change impacts in Europe across multiple sectors. Reg. Environ. Change 19, 695-709 (2019).

37. Frantzeskaki, N. et al. Transition pathways to sustainability in greater than 2 ${ }^{\circ} \mathrm{C}$ climate futures of Europe. Reg. Environ. Change 19, 777-789 (2019).

38. Hasegawa, T. et al. Risk of increased food insecurity under stringent global climate change mitigation policy. Nat. Clim. Change 8, 699-703 (2018).

39. Hanasaki, N. et al. A global water scarcity assessment under Shared Socio-economic Pathways - Part 2: water availability and scarcity. Hydrol. Earth Syst. Sci. 17, 2393-2413 (2013).

40. Park, C. et al. Avoided economic impacts of energy demand changes by 1.5 and $2{ }^{\circ} \mathrm{C}$ climate stabilization. Environ. Res. Lett. 13, 4 (2018).

41. IPCC Special Report on Global Warming of $1.5^{\circ} \mathrm{C}$ (eds Masson-Delmotte, V. et al.) (WMO, 2018) 
42. IPCC Special Report on Climate Change and Land (eds Shukla, P. R. et al.) (WMO, 2019)

43. IPCC Special Report on the Ocean and Cryosphere in a Changing Climate (eds Pörtner, H.-O. et al.) (WMO, 2019).

44. Global Assessment Report on Biodiversity and Ecosystem Services of the Intergovernmental Science-Policy Platform on Biodiversity and Ecosystem Services (IPBES, 2019).

45. TWI2050 Report: Transformations to Achieve the Sustainable Development Goals (IIASA, 2018).

46. Global Environment Outlook - GEO-6: Healthy Planet, Healthy People (United Nations Environment Programme, 2019).

47. O'Neill, B. C. et al. The Scenario Model Intercomparison Project (ScenarioMIP) for CMIP6. Geosci. Model Dev. 9, 3461-3482 (2016).

48. Rosa, I. M. D. et al. Challenges in producing policy-relevant global scenarios of biodiversity and ecosystem services. Glob. Ecol. Conserv. 22, e00886 (2020). Addresses the extension of scenarios to the biodiversity community.

49. Mason-D'Croz, D. et al. Multi-factor, multi-state, multi-model scenarios: exploring food and climate futures for Southeast Asia. Environ. Modell. Soft. 83, 255-270 (2016).

50. Cradock-Henry, N. A., Frame, B., Preston, B. L., Reisinger, A. \& Rothman D. S. Dynamic adaptive pathways in downscaled climate change scenarios. Climatic Change 150, 333-341 (2018).

51. van Ruijven, B. J. et al. Enhancing the relevance of Shared Socioeconomic Pathways for climate change impacts, adaptation and vulnerability research. Climatic Change 122, 481-494 (2014).

52. Scheffer, M. et al. Early-warning signals for critical transitions. Nature 461, 53-59 (2009).

53. Hazeleger, W. et al. Tales of future weather. Nat. Clim. Change 5, 107-113 (2015).

54. Shepherd, T. G. et al. Storylines: an alternative approach to representing uncertainty in physical aspects of climate change. Climatic Change 151, 555-571 (2018).

55. de Bruijn, K. M., Lips, N., Gersonius, B. \& Middelkoop, H. The storyline approach: a new way to analyse and improve flood event management. Nat. Hazards 81, 99-121 (2016).

56. Shepherd, T. G. Storyline approach to the construction of regional climate change information. P. Roy. Soc. A-Math. Phy. 475, 20190013 (2019).

57. Sillmann, J. et al. Physical Modeling Supporting a Storyline Approach (CICERO Center for International Climate and Environmental Research, 2019).

58. Giorgi, F. \& Gutowski, W. J. Regional dynamical downscaling and the CORDEX initiative. Annu. Rev. Env. Resour. 40, 467-490 (2015).

59. Challinor, A. J., Adger, W. N. \& Benton, T. G. Climate risks across borders and scales. Nat. Clim. Change 7, 621-623 (2017).

60. van Ruijven, B. J., De Cian, E. \& Sue Wing, I. Amplification of future energy demand growth due to climate change. Nat. Commun. 10, 2762 (2019).

61. Biggs, R. et al. Linking futures across scales: a dialog on multiscale scenarios. Ecol. Soc. 12, 17 (2007).

62. Zurek, M. B. \& Henrichs, T. Linking scenarios across geographical scales in international environmental assessments. Technol. Forecast. Soc. 74, 1282-1295 (2007).

63. Nilsson, A. E. et al. Towards extended shared socioeconomic pathways: a combined participatory bottom-up and top-down methodology with results from the Barents region. Glob. Environ. Change 45, 124-132 (2017).

64. Mitter, H. Shared Socio-economic Pathways for European agriculture and food systems: the Eur-Agri-SSPs. Glob. Environ. Change 65, 102159 (2020). Develops regional SSPs for application to the agricultural sector.

65. Kebede, A. S. et al. Applying the global RCP-SSP-SPA scenario framework at sub-national scale: a multi-scale and participatory scenario approach. Sci. Total Environ. 635, 659-672 (2018).

66. Tàbara, J. D. et al. Exploring institutional transformations to address high-end climate change in Iberia. Sustainability 10, 161 (2018)

67. Hunt, D. V. L. et al. Scenario archetypes: converging rather than diverging themes. Sustainability 4, 740-772 (2012).

68. van Vuuren, D. P., Kok, M. T. J., Girod, B., Lucas, P. L. \& de Vries, B. Scenarios in global environmental assessments: key characteristics and lessons for future use. Glob. Environ. Change 22, 884-895 (2012).

69. Guillaume Rohat, Johannes Flacke, Hy Dao, Martin van Maarseveen, (2018) Co-use of existing scenario sets to extend and quantify the shared socioeconomic pathways. Climatic Change 151 (3-4):619-636

70. Reidmiller, D. R. et al. (eds) Impacts, Risks, and Adaptation in the United States: Fourth National Climate Assessment Volume II (US Global Change Research Program, 2018).

71. Pereira, L. M. et al. Developing multi-scale and integrative nature-people scenarios using the Nature Futures Framework. People and Nature https:// doi.org/10.1002/pan3.10146 (2020).

72. O'Neill, B. C. et al. The roads ahead: Narratives for shared socioeconomic pathways describing world futures in the 21st century. Glob. Environ. Change 42, 169-180 (2017)
73. van Vuuren, D. P. et al. A proposal for a new scenario framework to support research and assessment in different climate research communities. Glob. Environ. Change 22, 21-35 (2012).

74. Grant, N., Hawkes, A., Napp, T. \& Gambhir, A. The appropriate use of reference scenarios in mitigation analysis. Nat. Clim. Change 10, 605-610 (2020).

75. Roelfsema, M. Taking stock of climate policies: future impact of national policies in the context of the Paris Agreement climate goals. Nat. Commun. 11, 2096 (2020)

76. Wilbanks, T. J. \& Ebi, K. L. SSPs from an impact and adaptation perspective. Climatic Change 122, 473-479 (2014).

77. Otero, I. et al. Biodiversity policy beyond economic growth. Conserv. Lett. 13, e12713 (2020).

78. Buhaug, H. \& Vestby, J. On Growth Projections in the Shared Socioeconomic Pathways. Global Environ. Polit. 19, 118-132 (2019).

79. Grubler, A. et al. A low energy demand scenario for meeting the $1.5{ }^{\circ} \mathrm{C}$ target and sustainable development goals without negative emission technologies. Nat. Energy 3, 515-527 (2018).

80. van Vuuren, D. P. et al. Alternative pathways to the $1.5^{\circ} \mathrm{C}$ target reduce the need for negative emission technologies. Nat. Clim. Change 8, 391-397 (2018).

81. Cash, D. W. et al. Knowledge systems for sustainable development. Proc. Natl Acad. Sci. USA 100, 8086-8091 (2003).

82. Beck, S. \& Mahony, M. The IPCC and the politics of anticipation. Nat. Clim. Change 7, 311-313 (2017).

83. Edenhofer, O. \& Kowarsch, M. Cartography of pathways: a new model for environmental policy assessments. Environ. Sci. Policy 51, 56-64 (2015).

84. Kowarsch, M. \& Jabbour, J. Solution-oriented global environmental assessments: opportunities and challenges. Environ. Sci. Policy 77 187-192 (2017).

85. Inayatullah, S. Deconstructing and reconstructing the future: predictive, cultural and critical epistemologies. Futures 22, 115-141 (1990).

86. Sardar, Z. Colonizing the future: the 'other' dimension of futures studies. Futures 25, 179-187 (1993).

87. Inayatullah, S. (eds) in The Causal Layered Analysis Reader: Theory and Case Studies of an Integrative and Transformative Methodology 1-52 (Tamkang Univ. Press, 2004).

88. Slaughter, R. A. From forecasting and scenarios to social construction: changing methodological paradigms in futures studies. Foresight $\mathbf{4}$, 26-31 (2002).

89. Schweizer, V. J. \& O’Neill, B. C. Systematic construction of global socioeconomic pathways using internally consistent element combinations. Climatic Change 122, 431-445 (2014).

90. Lamontagne, J. R. et al. Large ensemble analytic framework for consequence-driven discovery of climate change scenarios. Earth's Future 6, 488-504 (2018).

91. Carlsen, H., Lempert, R., Wikman-Svahn, P. \& Schweizer, V. Choosing small sets of policy-relevant scenarios by combining vulnerability and diversity approaches. Environ. Modell. Soft. 84, 155-164 (2016).

92. Clapp, C. \& Sillmann, J. Facilitating climate-smart investments. One Earth 1, 57-61 (2019).

93. Final Report: Recommendations of the Task Force on Climate-related Financial Disclosures (TCFD, 2017); https://www.fsb-tcfd.org/publications/ final-recommendations-report/

94. First Comprehensive Report: A Call For Action (NGFS, 2019); https://www. ngfs.net/en/first-comprehensive-report-call-action

95. Weber, C. et al. Mitigation scenarios must cater to new users. Nat. Clim. Change 8, 845-848 (2018)

96. Vaughan, C. \& Dessai, S. Climate services for society: origins, institutional arrangements, and design elements for an evaluation framework: climate services for society. WIREs Clim. Change 5, 587-603 (2014).

97. Rogelj, J. et al. A new scenario logic for the Paris Agreement long-term temperature goal. Nature 573, 357-363 (2019).

98. Green, C. et al. Shared Socioeconomic Pathways (SSPs) Literature Database, v1, 2014-2019 (NASA Socioeconomic Data and Applications Center (SEDAC), 2020); https://doi.org/10.7927/HN96-9703

99. Kriegler, E. et al. The need for and use of socio-economic scenarios for climate change analysis: a new approach based on shared socio-economic pathways. Glob. Environ. Change 22, 807-822 (2012).

100. KC, S. \& Lutz, W. The human core of the shared socioeconomic pathways: population scenarios by age, sex and level of education for all countries to 2100. Glob. Environ. Change 42, 181-192 (2017).

101. Dellink, R., Chateau, J., Lanzi, E. \& Magné, B. Long-term economic growth projections in the Shared Socioeconomic Pathways. Glob. Environ. Change 42, 200-214 (2017).

102. Crespo Cuaresma, J. Income projections for climate change research: a framework based on human capital dynamics. Glob. Environ. Change 42, 226-236 (2017).

103. Leimbach, M., Kriegler, E., Roming, N. \& Schwanitz, J. Future growth patterns of world regions - a GDP scenario approach. Glob. Environ. Change 42, 215-225 (2017). 
104. Jiang, L. \& O’Neill, B. C. Global urbanization projections for the Shared Socioeconomic Pathways. Glob. Environ. Change 42, 193-199 (2017).

105. Gidden, M. J. et al. Global emissions pathways under different socioeconomic scenarios for use in CMIP6: a dataset of harmonized emissions trajectories through the end of the century. Geosci. Model Dev. 12, 1443-1475 (2019).

106. Taylor, K. E., Stouffer, R. J. \& Meehl, G. A. An overview of CMIP5 and the experiment design. Bull. Amer. Meteor. Soc. 93, 485-498 (2011).

107. Frame, B., Lawrence, J., Ausseil, A.-G., Reisinger, A. \& Daigneault, A. Adapting global shared socio-economic pathways for national and local scenarios. Clim. Risk Manag. 21, 39-51 (2018).

A regional extension to the framework that points the way to accommodating adaptation policy.

108. Spangenberg, J. H. et al. Scenarios for investigating risks to biodiversity. Global Ecol. Biogeogr. 21, 5-18 (2012).

109. Le Quéré, C. et al. Temporary reduction in daily global $\mathrm{CO}_{2}$ emissions during the COVID-19 forced confinement. Nat. Clim. Change 10, 647-653 (2020).

110. Forster, P. M. et al. Current and future global climate impacts resulting from COVID-19. Nat. Clim. Change 10, 913-919 (2020).

111. Samset, B. H., Fuglestvedt, J. S. \& Lund, M. T. Delayed emergence of a global temperature response after emission mitigation. Nat. Commun. 11, 3261 (2020)

112. David Tàbara, J. et al. Positive tipping points in a rapidly warming world. Curr. Opin. Env. Sust. 31, 120-129 (2018).

113. Scheidel, W. The Great Leveler: Violence and the History of Inequality from the Stone Age to the Twenty-First Century (Princeton Univ. Press, 2018).

114. Osterhammel, J. The Transformation of the World: A Global History of the Nineteenth Century (Princeton Univ. Press, 2015).

115. Raskin, P. \& Swart, R. Excluded futures: the continuity bias in scenario assessments. Sustain. Earth 3, 8 (2020).

116. Kaivo-oja, J. Weak signals analysis, knowledge management theory and systemic socio-cultural transitions. Futures 44, 206-217 (2012).

117. Harrison, P.A., Harmáčková, Z. \& Pedde, S. Online Workshop on Co-creating UK Socio-economic Scenarios: Summary of Workshop Output on Drivers of Future Socio-economic Development and their Mapping to the Shared Socio-economic Pathways (UK Centre for Ecology \& Hydrology, 2020); https://www.camecon.com/wp-content/uploads/2020/06/ UK-SSPs-Workshop_Preliminary_Results_on_Drivers.pdf

\section{Acknowledgements}

We thank all participants in Scenarios Forum 2019 for their contributions to developing, using and assessing the scenario framework. The following authors gratefully acknowledge funding: B.C.O. for support of the Scenarios Forum from the ClimateWorks Foundation, the Pardee Center for International Futures and the University of Denver; K.R. and B.v.R. from the European Union's Horizon 2020 research and innovation programme under grant agreements no. 821471 (ENGAGE) and 642147 (CD-LINKS); P.A.H. from the Natural Environment Research Council (UK-SCAPE programme: $601 \mathrm{NE} / \mathrm{R} 016429 / 1$ ) and the Met Office (Climate Resilience Strategic Priority Fund: DN420214 - CR19-3); T.R.C. from the European Commission (R\&I Action 821010) and Academy of Finland (Decisions 329223 and 330915); T.H. from the Environment Research and Technology Development Fund (JPMEERF20202002) of the Environmental Restoration and Conservation Agency of Japan and JSPS KAKENHI (19K24387) and the Sumitomo Foundation.

\section{Author contributions}

B.C.O. coordinated, and all authors contributed to, the study design and drafting of the manuscript. T.R.C., K.E., P.A.H., E.K.-B., K.K., E.K., B.C.O., B.L.P., K.R., J.S., B.v.R. and D.v.V. led the drafting of specific sections of the manuscript. D.C., C.G. and B.C.O. carried out the literature review and coding. B.C.O. prepared the figures.

\section{Competing interests}

The authors declare no competing interests.

\section{Additional information}

Supplementary information is available for this paper at https://doi.org/10.1038/ s41558-020-00952-0.

Correspondence should be addressed to B.C.O.

Reprints and permissions information is available at www.nature.com/reprints.

Publisher's note Springer Nature remains neutral with regard to jurisdictional claims in published maps and institutional affiliations.

Peer review statement Nature Climate Change thanks Judy Lawrence, Edward Parson and the other, anonymous, reviewer(s) for their contribution to the peer review of this work.

(C) Springer Nature Limited 2020 